\title{
ALGORITMA ASSOCIATION RULE DENGAN METODE FP-GROWTH UNTUK MENGANALISA TINGKAT PENYALAHGUNAAN NARKOBA (STUDI KASUS POLRES PADANG PARIAMAN)
}

\author{
Agung Putra Yunanda, Hilda Rahmawati, Irfan Fadhli, Esti Purnomo \\ Universitas Pembinaan Masyarakat Indonesia \\ Email: agungputrayunanda69@gmail.com \\ Email: hildarahma2708@gmail.com \\ Email: irfanfadhli74@gmail.com \\ Email: estipurnomo27@gmail.com
}

\begin{abstract}
Abstrak
Perkembangan kasus penyalahgunaan narkoba di Indonesia beberapa kurun waktu terakhir ini menunjukkan tingkat kenaikan yang sangat mengkhwatirkan. Narkoba merupakan zat adiktif yang biasa dipakai dibidang kesehatan. Akan tetapi, penyalahgunaan narkotika dan obat-obatan terlarang tersebut kian meningkat. Maraknya penyimpangan perilaku oleh generasi muda tersebut dapat merusak masa depan danberlangsungnya kehidupan menjadi terganggu di waktu yang akan datang. Sehubungan dengan terjadinya masalah tersebut dilakukan teknik data mining untuk menganalisa tingkat penggunaan seseorang mengkonsumsi narkoba dengan metode fpgrowth. Adapun teknik yang digunakan dalam hal ini adalah Algoritma FP-Growth. FP-Growth adalah salah satu alternatif algoritma yang dapat digunakan untuk menentukan himpunan data yang paling sering muncul (frequent itemset) dalam sekumpulan data. Algoritma FP-Growth merupakan pengembangan dari algoritma Apriori. Sedangkan di dalam algoritma FP-Growth tidak dilakukan generate candidate karena FP-Growth menggunakan konsep pembangunan tree dalam pencarian frequent itemset. jenis tingkat kasus penyalahgunaan narkoba menggunakan association rule metode FP-Growth dapat membantu pengelompokan varibael - variable yang terdapat pada sebuah kasus serta menghasilkan sebuah pengetahuan baru
\end{abstract}

Kata kunci : Data Mining, Association Rules, FP-Growth, Frequent Itemset, Apriori

ASSOCIATION RULE ALGORITHM WITH FP-GROWTH METHOD TO ANALYSIS OF DRUG ABUSE (CASE STUDY OF PADANG PARIAMAN POLRES)

\begin{abstract}
The development of drug abuse cases in indonesia in the last few years shows an alarming rate of increase. Drugs are addictive substances commonly used in the health sector. However, the abuse of narcotics and illegal drugs is increasing. The rampant
\end{abstract}


deviance of behavior by the young generation can destroy the future and the continuity of life becomes disrupted in the future. In connection with this problem, data mining techniques are carried out to analyze the level of use of a person consuming drugs using the fp-growth method. The technique used in this case is the fp-growth algorithm. Fp-growth is an alternative algorithm that can be used to determine the most frequent itemset in a data set. The fp-growth algorithm is a development of the apriori algorithm. Meanwhile, in the fp-growth algorithm, there is no generating candidate because fp-growth uses the concept of building a tree in the search for frequent itemset. The type of drug abuse case level using the association rule, the fp-growth method can help group the variables in a case and generate new knowledge

Keywords: data mining, association rules, fp-growth, frequent itemset, apriori.

\section{PENDAHULAN}

Penyalahgunaan dalam penggunaan narkoba adalah pemakain obat-obatan atau zat-zat berbahaya dengan tujuan bukan untuk pengobatan dan penelitian serta digunakan tanpa mengikuti aturan atau dosis yang benar. Masalah penyalahgunaan narkoba, khususnya di Indonesia, saat ini telah sampai pada tingkat yang mengkhawatirkan. Jumlah pengguna dan pecandu narkoba dari tahun ke tahun kian menunjukkan angka peningkatan. Narkoba merupakan zat adiktif yang biasa dipakai dibidang kesehatan. Sasaran utama penyalahgunaan narkoba adalah para remaja, karena masa remaja merupakan masa transisi (peralihan) dari masa anak-anak menuju masa dewasa dan di masa inilah seseorang biasanya mengalami perubahan yang sangat fundamental dalam kehidupannya baik fisik maupun psikis.

Narkoba sebagai kependekan dari Narkotika dan Obat-obatan terlarang, menurut Pasal 1 angka 1 UU No. 22 Tahun 1997 tentang

Narkotika. Begitu pula, menurut Pasal 1 angka 1 UU No. 5 Tahun 1997 tentang Psikotropika. Salah satu metode yang dapat digunakan untuk masalah tersebut adalah dengan metode Association Rule.

Apriori adalah salah satu algoritma yang sangat dikenal dalam melakukan pencarian frequent itemset dengan menggunakan teknik association rule ( Lingga D., 2016). Association rule adalah salah satu cara teknik dalam analisis yang untuk mencari hubungan antar item dalam suatu dataset dan mengetahui aturan asosiasi yang bersifat objektif untuk mengukur integritas di antara dua pola aturan asosiasi yang telah diekstrak menggunakan ukuran objektif untuk mencari hubungan antar item dalam suatu dataset dalam bentuk aturan asosiasi.(Datta S., dan Mali K., 2016).

Data Mining adalah sebuah proses yang mencari dan menemukan sebuah hubungan ataupun pola dengan memeriksa dalam sekumpulan data yang telah tersimpan dengan menggunakan teknik hubungan dan pola seperti statistic dan matematika. Data mining digunakan untuk ekstraksi informasi penting yang tersembunyi dari dataset yang besar. Dengan adanya data mining maka akan didapatkan suatu permata berupa pengetahuan di dalam kumpulan data - data yang 
banyak jumlahnya (Than T., Sihwi S.W, dan Anggrainingsih R., 2015). Algoritma FPGrowth adalah sebuah rekomendasi keputusan.Association Rule mengasosiasikan satu atau lebih atribut sebuah dataset dengan atribut lain. Untuk menemukan hidden dan hubungan yang signifikan antara atribut menghasilkan if then pernyataan tentang nilai atribut dalam bentuk aturan (Ikhwan A., Nofriansyah D., dan Sriani., 2015)

Dalam penelitian ini akan dilakukan pengujian apakah metode Association Rule Algoritma FP-Growth dapat digunakan untuk menyelesaikan permasalahan pada data Penyalahgunaan Narkoba. Hasil dari penelitian ini diharapkan dapat memberikan informasi potensi Penyalahgunaan Narkoba yang dapat terjadi dan membantu pihak kepolisian dalam mengantisipasi Penyalahgunaan Narkoba yang sering muncul. Dengan latar belakang ini maka penulis melakukan penelitian yang berjudul "ALGORITMA ASSOCIATION RULE DENGAN METODE FP-GROWTH UNTUK MENGANALISA TINGKAT PENYALAHGUNAAN NARKOBA (STUDI KASUS POLRES PADANG PARIAMAN)"

\section{METODE PENELITIAN}

\section{Kerangka Pemikiran}

Penelitian merupakan suatu proses mencari sesuatu secara sistematis dalam waktu yang relatif lama dengan menggunakan metode ilmiah berdasarkan prosedur dan peraturan yang berlaku.

Kegiatan penelitian memerlukan sebuah metodologi yang berisi kerangka pemikiran. Kerangka pemikiran merupakan gambaran dari langkah-langkah yang akan dilaksanakan agar penelitian dapat berjalan secara sistematis dan tujuan yang diharapkan dapat tercapai

\section{Kerangka Kerja}

Kerangka kerja ini merupakan langkah-langkah yang akan dilakukan dalam penyelesaian masalah yang akan dibahas. Di mana dari kerangka kerja ini akan kita ketahui langkah mulai dari awal sampai berakhirnya penelitian. Berikut ini merupakan gambaran umum kerangka pemikiran dalam penelitian ini :

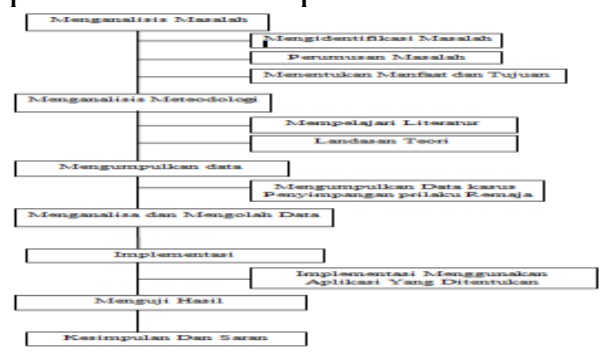

Gambar 1 Tentang Kerangka Kerja Penelitian 
Berdasarkan gambar 1 tentang kerangka kerja penelitian, gambar tersebut merupakan langkah-langkah yang dilaksanakan. Berikut ini penjelasan masing-masing langkahnya dapat diuraikan seperti berikut ini :

1. Menganalisis Masalah

Ruang lingkup masalah yang akan diteliti terlebih dahulu harus ditentukan, agar dapat diidentifikasikan masalah yang terjadi dan mengetahui batasan-batasan masalah yang akan diteliti agar didapatkan solusi yang terbaik dari masalah tersebut. Serta menentukan manfaat dan tujuan yang akan dicapai dari suatu penelitian. Jadi ini merupakan langkah awal yang terpenting dalam penulisan ini.

Dalam menganalisis masalah penelitian ini, akan dilakukan Metode Deskriptif, di mana data terlebih dahulu dikumpulkan, kemudian disusun serta dianalisis agar diperoleh beberapa gambaran pada masalah yang akan dibahas. Kemudian Metode Komperatif, di mana metode ini dilakukan dengan cara membandingkan praktek dengan teori. Sehingga dapat diperoleh gambaran yang jelas dan dapat diketahui perbedaan dan persamaan antara keduanya.

2. Menganalisis Metodologi

Menganalisis Metodologi mempelajari literatur-literatur yang bisa digunakan. Teori tentang Algoritma Apriori, Data Mining dan Metode FP-growth di mana literatur ini diambil dari artikel dan jurnal ilmiah yang ada di internet.

3. Mengumpulkan Data

Dalam pengumpulan data ini akan dilakukan terlebih dahulu pemahaman tentang Penyalahgunaan Narkoba dan dilakukan pengambilan data berupa informasi Penyalahgunaan Narkoba pada Polres Padang Pariaman.

4. Menganalisa Dan Mengolah Data

Pada tahap ini akan dilakukan mengolah data dan dianalisis data yang telah dikumpulkan. Analisis menggunakan Association Rule yang dimaksud dilakukan melalui mekanisme perhitungan support dan confidence dari

suatu hubungan item. Sebuah rule asosiasi dikatakan interesting jika nilai support adalah lebih besar dari minimum support dan juga nilai confidence adalah lebih besar dari minimum confidence. Dengan menggunakan teknik FP-Growth yang menghasilkan Frequent Itemset tanpa melakukan candidates generation. Dengan tujuan untuk mendapatkan pengetahuan yang baru (knowledge) berupa informasi tentang tindakan Penyalahgunaan Narkoba yang kerap sering kali terjadi dalam kehidupan bermasyarakat. Metode $\mathrm{FP}$-Growth dapat dibagi menjadi 3 tahapan utama yaitu sebagai:

1. Tahap Pembangkitan Conditional Pattern Base

Conditional Pattern Base merupakan subdatabase yang berisi prefix path (lintasan prefix) dan suffix pattern (pola akhiran). Pembangkitan conditional pattern base didapatkan melalui $F P$-Tree yang telah dibangun sebelumnya.

2. Tahap Pembangkitan Conditional FP-Tree 
Pada tahap ini, support count dari setiap item pada setiap conditional pattern base dijumlahkan, lalu setiap item yang memiliki jumlah support count lebih besar sama dengan minimum support count $\xi$ akan dibangkitkan dengan conditionalFP-Tree.

3. Tahap Pencarian Frequent Itemset

Lintasan tunggal (single path), maka didapatkan frequent itemset dengan melakukan kombinasi item untuk setiap conditional FP-Tree. Jika bukan lintasan tunggal, maka dilakukan pembangkitan $F P$-growth secara rekursif.

\section{Implementasi}

Setelah rancangan selesai, maka pada tahap ini dilakukan uji coba terhadap program sehingga analisis hasil implementasi dari pengujian ini menggunakan perangkat keras (hardware) yang diperlukan untuk penelitian ini berupa printer canon iP2770 intel inside core i5vPro, laptop ASUS dan juga menggunakan perangkat lunak (software) aplikasi WEKA yang dapat memudahkan pekerjaan dalam mengolah data. Jika penerapan sistem sudah berjalan dengan baik, selanjutnya dapat diimplementasikan sesuai dengan kebutuhan yang diinginkan.

6. Menguji Hasil

Pada tahap ini dilakukan pengujian untuk mengetahui hasil pengelompokan data penyimpangan perilaku yang dibantu sebuah softwere Data Mining yaitu WEKA.

Mekanisme yang dilakukan saat pengujian sistem adalah :

1. Mengelompokkan Data Mentah

2. Memberi kode untuk setiap data agar mudah dikenali

3. Menghitung frekuensi kemunculan pada setiap item

4. Membuat $f p$-tree dan menentukan frequent itemset

5. Menghitung nilai support dan confidence

6. Menentukan rule yang akan dipakai

7. Kesimpulan dan Saran

Ini merupakan tahap akhir dari penelitian ini yang berisi tentang rangkuman dari keseluruhan hasil penelitian yang telah dilakukan tentang penyalahgunaan narkoba, sedangkan saran merupakan usul ataupun pendapat dari penulis yang mengacu pada materi pembahasan dan kemungkinan dapat dilaksanakan.

\section{HASIL DAN PEMBAHASAN}

\section{Sumber Data Penelitian}

Dalam penelitian ini sumber daya yang digunakan data yang belum diolah pada kasus penyalahgunaan narkoba yang terjadi didaerah Sumatera Barat Kabupaten Padang Pariaman, data diperoleh dengan cara memintak izin penelitian disertai dengan surat izin penelitian dan pembambil data dari kampus. Data penyalahgunaan narkoba yang mencangkup laporan hasil tangkapan penyalahgunaan narkoba di Satresnarkoba Polres 
Padang Pariaman data yang dicatat dan yang telah diambil memiliki atribut tersangka, jenis narkoba, dan tempat kejadian perkara. Keterangan data yang didapatkan dan telah digolongkan kepada kategorinya masing - masing : keterangan tersangka adalah Wiraswasta, Swasta, Pedagang, Petani, Sopir, Ibu Rumah Tangga dan Mahasiswa. Selanjutnya keterangan jenis narkoba yang digunakan adalah Shabu, Ganja Kering. Berikutnya merupakan keterangan tentang tempat kejadian, tempat sesuai kejadian di Kabupaten Padang Pariaman yaitu : Kec. 2X11 Kayu Tanam, Kec.2X11 Enam Lingkung, Kec. Lubuk Alung, Kec. VII Koto Sungai Sariak, Kec. Enam Lingkung, Kec. Batang Anai, Kec. Nan Sabaris, Kec. Ulakan Tapakis, dan, Kec. Toboh Gadang. Menentukan Frequent itemset dapat ditunjukan dengan bagan berikut:

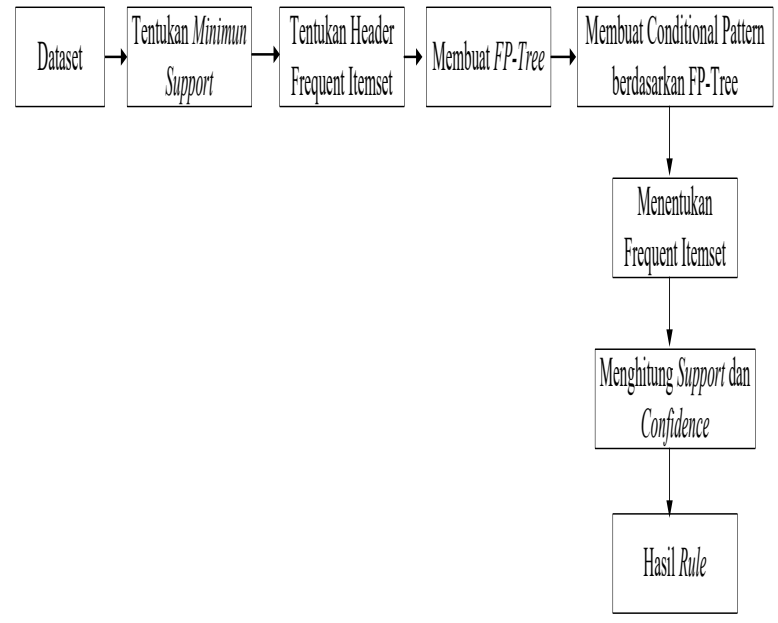

Gambar 2. Algoritma FP-Growth

Tabel 1. Data Kasus Hasil Pemindaian

\begin{tabular}{|c|c|}
\hline Item & Frekuensi \\
\hline N1 & 34 \\
\hline T1 & 22 \\
\hline T2 & 13 \\
\hline K3 & 12 \\
\hline
\end{tabular}




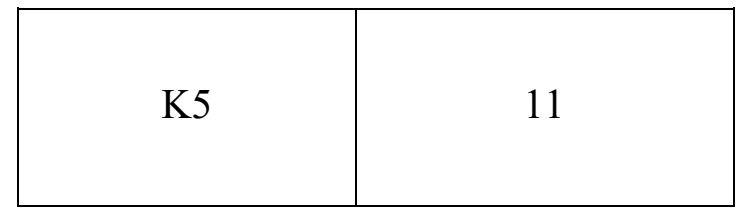

Pada tabel 1 Data Kasus Hasil pemindaian yaitu Frekuensi kemunculan transaksi yang mengandung suatu pola yang diambil item dan frekuensi dari yang tertinggi dan terendah dan hasil pemindaian yang memiliki frekuensi di atas support count $\xi=10$ adalah N1,T1,T2,K3 dan K5.

Selanjutnya menghitung support dan confidence dari hasil pembentukan fp-tree yang sudah di lakukan.

support $=\frac{\sum \text { jumlah Kasus }}{\sum \text { jumlah seluruh kasus }} \times 100 \%$

Untuk $\Sigma$ Item pada kasus \{ if Lubuk Alung (K3), Shabu (N1) then Wiraswasta (T1) ada 5 dari 42 kasus sehingga untuk Support nya adalah $5 / 42 * 100 \%=12 \%$

Confidence $=\frac{\sum \text { jumlah Kasus }}{\sum \text { Jumlah Kasus Pada Antecedent }} \times 100 \%$

Untuk $\Sigma$ Item pada kasus , $\{$ if Lubuk Alung (K3), Shabu (N1) then Wiraswasta (T1) ada 5 dan Lubuk Alung (K3), Shabu (N1) ada 8 sehingga untuk Confidence nya adalah $5 / 8 * 100 \%=63 \%$.

Dari rule yang didapat, berikut ini merupakan rule yang memiliki Support $\geq 11$ $\%$ dan memilki Confidence $\geq 63 \%$ seperti pada tabel 2 .

Tabel 2. Hasil Rule

\begin{tabular}{|l|c|c|}
\hline $\begin{array}{l}\text { If Antecedent then } \\
\text { Consequent }\end{array}$ & Support & Confidence \\
\hline $\begin{array}{l}\text { If Shabu (N1) then } \\
\text { Wiraswasta (T1) }\end{array}$ & $17 / 42=40 \%$ & $17 / 34=50 \%$ \\
\hline $\begin{array}{l}\text { If Wiraswasta } \\
\text { (T1) then Shabu } \\
\text { (N1) }\end{array}$ & $17 / 42=40 \%$ & $17 / 22=77 \%$ \\
\hline $\begin{array}{l}\text { If Swasta (T2) } \\
\text { then Shabu (N1) }\end{array}$ & $10 / 42=24 \%$ & $10 / 13=77 \%$ \\
\hline $\begin{array}{l}\text { If Lubuk Alung } \\
\text { (K3) then Shabu } \\
\text { (N1) }\end{array}$ & & \\
\hline $\begin{array}{l}\text { If Lubuk Alung } \\
\text { (K3) then }\end{array}$ & $7 / 42=17 \%$ & $7 / 12=58 \%$ \\
Wiraswasta (T1) & & \\
\hline
\end{tabular}




\begin{tabular}{|l|l|l|}
\hline If Enam Lingkung & $11 / 42=26 \%$ & $11 / 11=100 \%$ \\
(K5) then Shabu \\
(N1)
\end{tabular}

Setelah didapatkan rule yang mempunyai Confidence $\geq 63 \%$ kemudian di tentukan rule yang memenuhi kebutuhan, maka dapat disimpulkan rule yang terbaik adalah Jika Tempat Kejadian Perkara di Lubuk Alung dan Jenis Narkoba Shabu maka Tersangka adalah Wiraswasta.

\section{IMPLEMENTASI DAN HASIL}

\section{Implementasi}

Implementasi sistem tujuannya agar dapat mengetahui apakah sistem yang dibangun dapat berjalan dengan baik dan sudah sesuai dengan kententuan spesifikasi yang telah ditetapkan sebelumnya. Dengan implementasi ini maka semua hal yang berhubungan dengan ketentuan yang telah dibuat dalam bab analisa dan perancangan sistem telah dipenuhi sesuai dengan spesifikasi yang telah ditetapkan. Pada implementasi inilah suatu sistem dapat diketahui apakah suatu sistem tersebut memiliki kekurangan atau pun error. Baik itu kesalahan dalam pengisian data, maupun kesalahan dalam pengujian. Semua itu dapat kita temukan jika prosedur implementasi telah diikuti dengan benar dan selesai dilakukan. Prosedur implementasi akan dipaparkan pada sub bab berikutnya. Untuk melihat tingkat keberhasilan suatu proses dalam pengolahan data, yaitu dengan melihat apakah semua data telah diproses.

\section{Lingkungan Implementasi}

Dalam lingkungan implementasi, komputer merupakan alat bantu yang sangat berpengaruh dalam pengujian data mining dengan spesifikasi sebagai berikut:

A. Komputer
1) Hardware
a.Laptop ASUS
b.Processor Intel ${ }^{\complement}$ Inside Core $^{\mathrm{Tm}}$ i3 $3217 U$ 


\section{c. Memory $4 \mathrm{~Gb}$ \\ 2) Software \\ a. Microsoft Windows \\ b. Software WEKA.}

\section{Implementasi Program}

Implementasi program merupakan hasil dari analisa aplikasi yang digunakan untuk mengolah data. Untuk mengimplementasikan program Data Mining seperti Weka dapat dilakukan dengan melakukan penginstalan seperti menginstal aplikasi lainnya. Setelah aplikasi tersebut diinstal, selanjutnya penulis dapat melakukan analisa terhadap data yang akan diolah.

1. Buatlah sebuah file di Notepad seperti gambar di bawah ini.

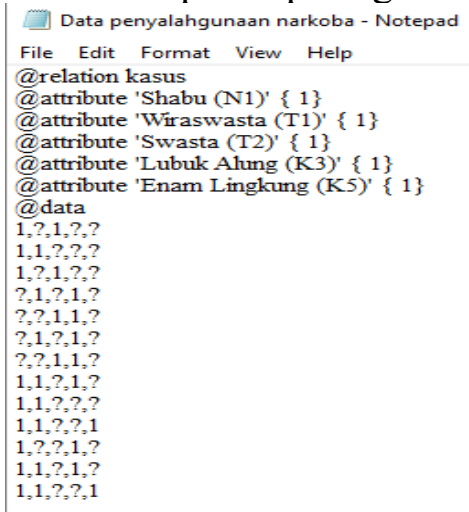

Gambar 3. Pembuatan Data Format .Arff Pada Notepad

2. Setelah data diketik semuanya kedalam Notepad maka data tersebut disimpan dalam format "arff", karena hanya data dalam format "arff" yang dapat dibaca oleh program WEKA dalam menjalankan fungsi Fp-growth.

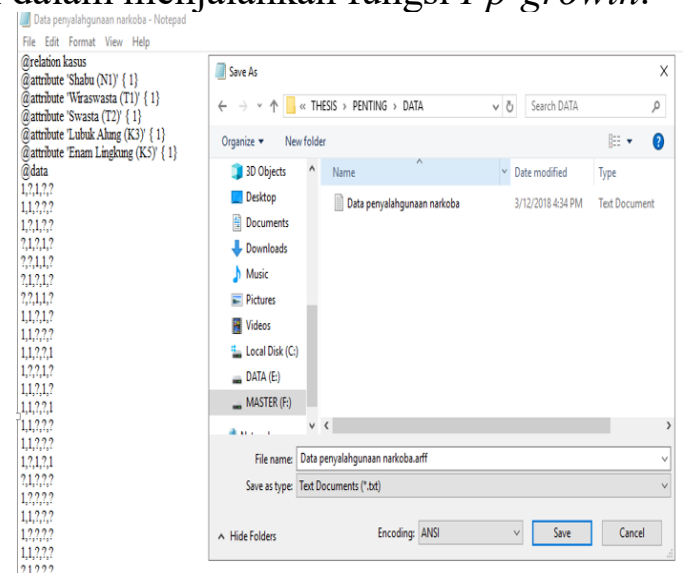

Gambar 4. Format Penyimpan Data 
3. Sebelum melakukan pengujian terhadap data kita harus memastikan data yang kita buat sesuai dengan seharusnya dengan cara membuka program WEKA seperti gambar dibawah ini:

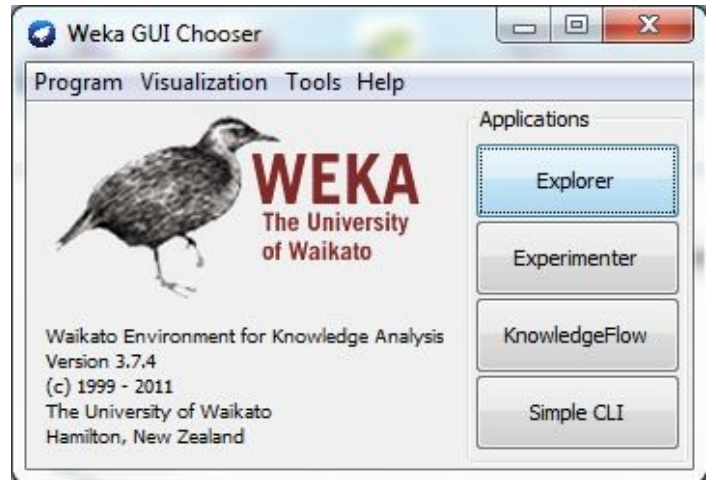

Gambar 5. Tampilan Awal Weka

Selanjutnya pilih menu "Tools" kemudian pilih "Arffviewer" seperti gambar di bawah ini :

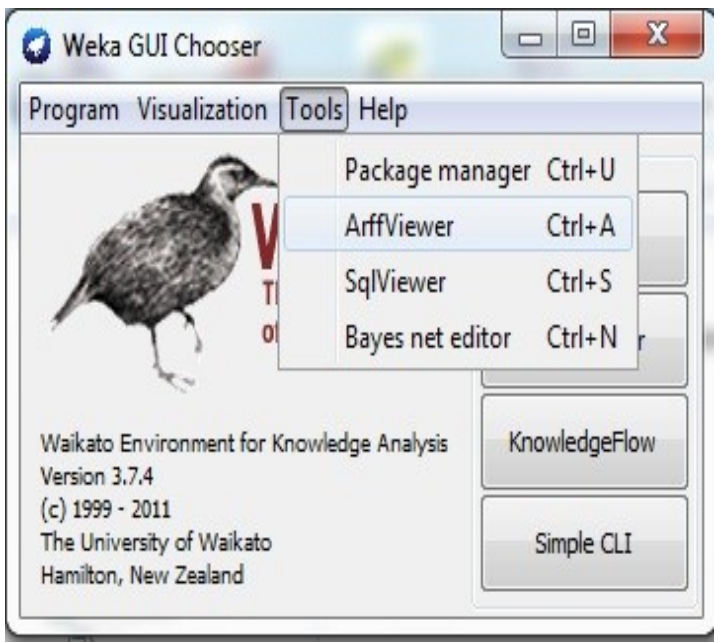

Gambar 6. Langkah 1 Arffviewer Pada Weka

Pilih "Open" pada menu "File"

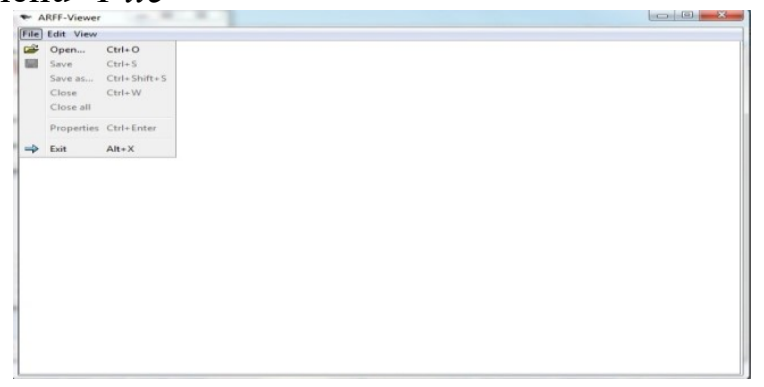

Gambar 7. Langkah 2 Arffviewer Pada Weka 
Cari data "arff" yang dibuat seperti gambar di bawah ini :

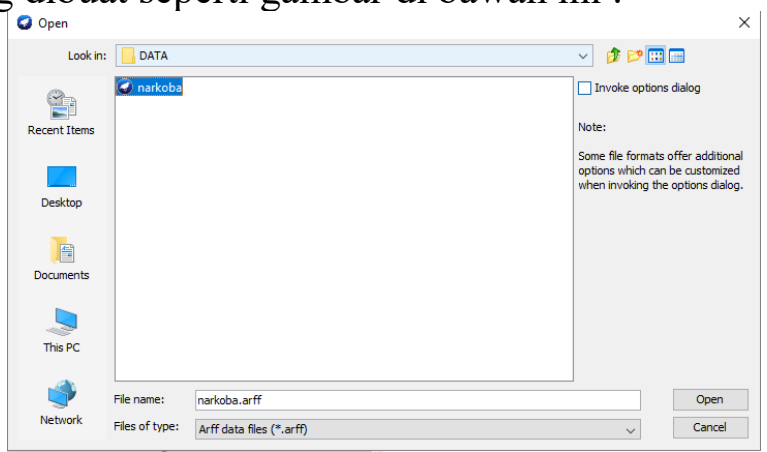

Gambar 8. Langkah 3 Arffviewer Pada Weka

Maka akan terlihatlah data "arff" yang dibuat tadi yang bisa dilihat pada gambar di bawah ini :

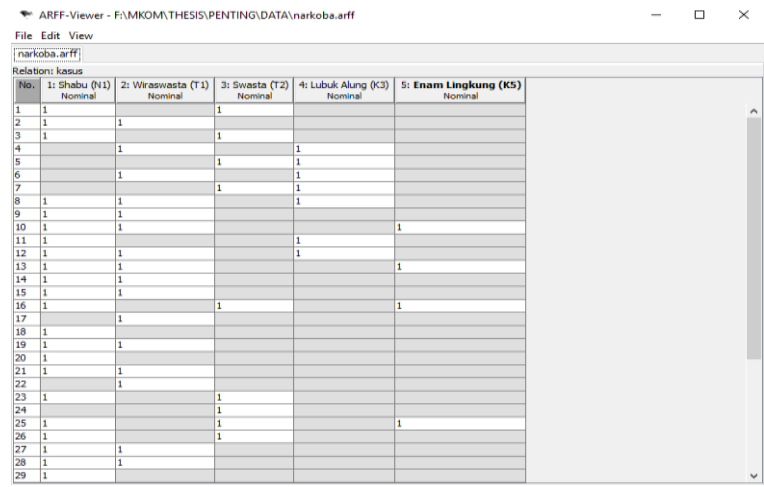

Gambar 9. Data Penyalahgunaan Narkobaa Arff pada Weka

Pada gambar 9 bisa dilihat atribut yang muncul dari setiap kasus yang ditandai menggunakan angka "1" sesuai dengan atribut yang muncul pada data aslinya.

4. Selanjutnya untuk pengujian data yang telah disimpan dibuka dengan memilih "Explorer" pada bagian menu awal WEKA, seperti yang terlihat pada gambar di bawah ini:

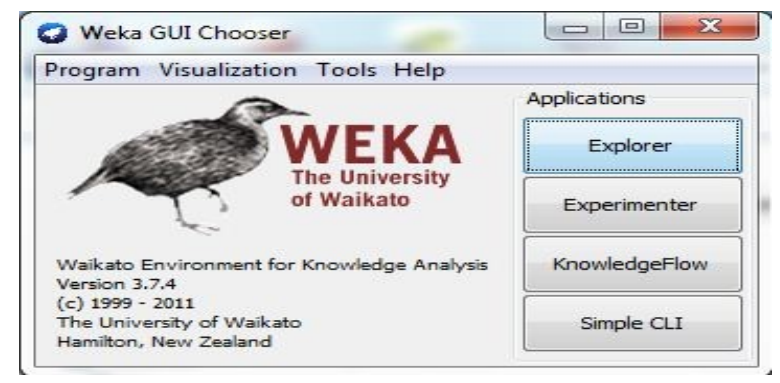

Gambar 10. Tampilan Awal Program WEKA 
5. Setelah itu akan muncul gambar seperti di bawah ini, kemudian pilih "Open file" dan silahkan masukkan datanya dan pilih open.

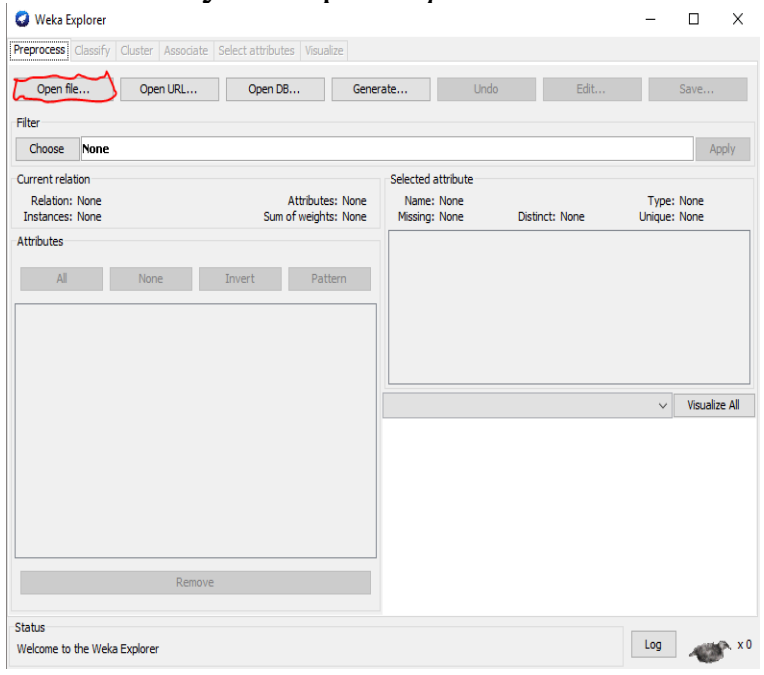

Gambar 11. Tampilan untuk memilih Data

6. Setelah itu lakukan pemilihan atribut yang dibutuhkan, seperti gambar di bawah ini

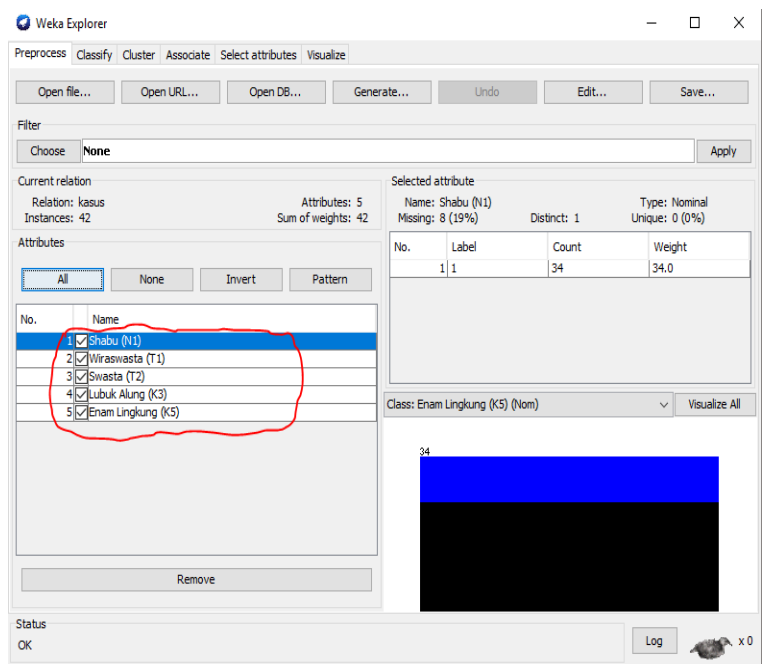

Gambar 12. Tampilan input Data

Dari gambar 12 bisa dijelaskan bahwa pada data Penyalahgunaan Narkoba semua atribut yang ada harus ditandai agar aplikasi WEKA bisa melakukan proses dengan benar.

7.Maka akan muncul hasil seperti yang terlihat di gambar di bawah ini : 


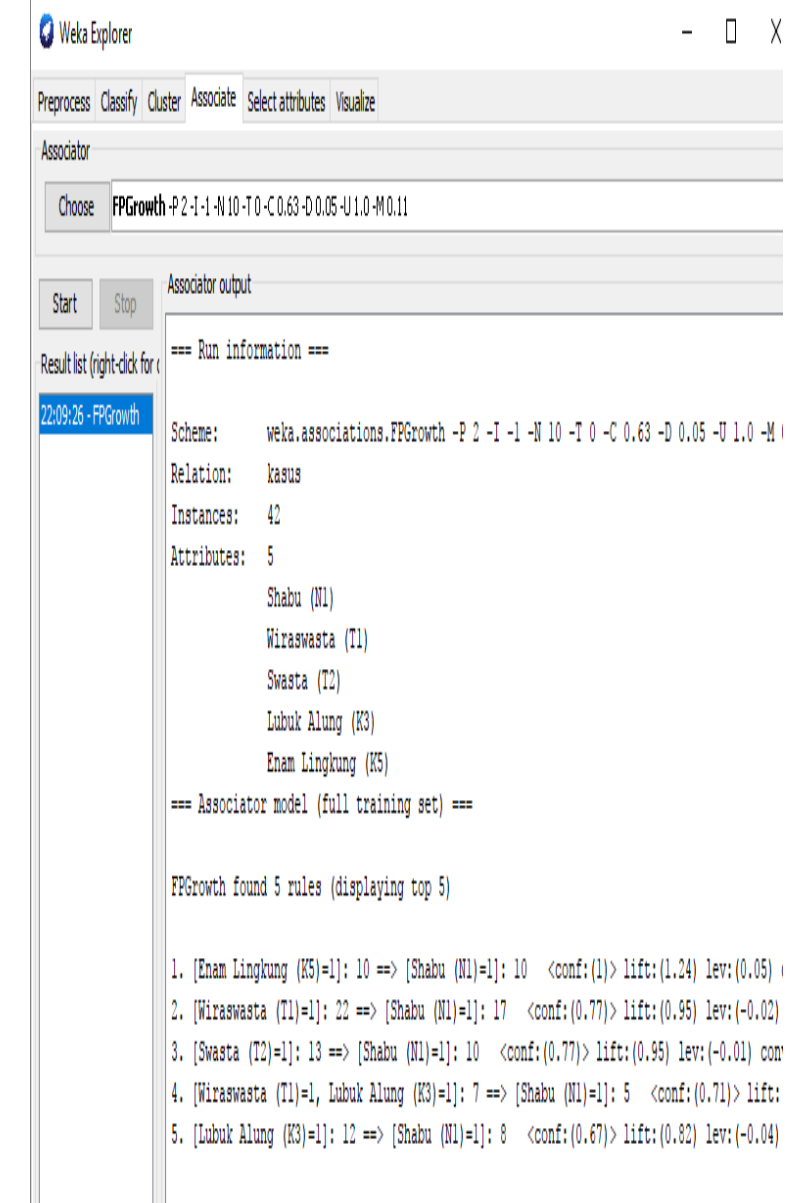

Gambar 13. Hasil Perhitungan Metode Fp-growth

Hasil diatas merupakan hasil dari rule dari jumlah data sebanyak 42 dan dapat dilihat bahwa rule yang didapat ada 5 yang memiliki nilai confidence di atas $63 \%$ yang diperjelas pada dibawah

Tabel 3. Hasil Rule Yang Terpilih Perhitungan Manual

\begin{tabular}{|c|c|c|c|}
\hline No & $\begin{array}{c}\text { Hasil Rule } \\
\text { Perhitungan } \\
\text { Manual }\end{array}$ & Support & Confidence \\
\hline 1 & $\begin{array}{c}\text { If Enam } \\
\text { Lingkung (K5) } \\
\text { then Shabu (N1) }\end{array}$ & $26 \%$ & $100 \%$ \\
\hline 2 & $\begin{array}{c}\text { If Wiraswasta } \\
\text { (T1) then Shabu } \\
\text { (N1) }\end{array}$ & $40 \%$ & $77 \%$ \\
\hline 3 & $\begin{array}{c}\text { If Swasta (T2) } \\
\text { then Shabu (N1) }\end{array}$ & $24 \%$ & $77 \%$ \\
\hline
\end{tabular}




\begin{tabular}{|c|c|c|c|}
\hline 4 & $\begin{array}{c}\text { If } \text { Lubuk Alung } \\
\text { (K3), Shabu } \\
\text { (N1) then } \\
\text { Wiraswasta } \\
\text { (T1) }\end{array}$ & $12 \%$ & $63 \%$ \\
\hline 5 & $\begin{array}{c}\text { If Lubuk Alung } \\
\text { (K3) then Shabu } \\
\text { (N1) }\end{array}$ & $19 \%$ & $67 \%$ \\
\hline
\end{tabular}

Tabel 4. Hasil Rule Yang Terpilih Perhitungan Dengan Aplikasi Weka

\begin{tabular}{|c|c|c|c|}
\hline No & $\begin{array}{c}\text { Hasil Rule } \\
\text { Perhitungan } \\
\text { Dengan Aplikasi } \\
\text { Weka }\end{array}$ & Support & Confidence \\
\hline 1 & $\begin{array}{c}\text { If Enam } \\
\text { Lingkung (K5) } \\
\text { then Shabu (N1) }\end{array}$ & $26 \%$ & $100 \%$ \\
\hline 2 & $\begin{array}{c}\text { If Wiraswasta } \\
\text { (T1) then Shabu } \\
\text { (N1) }\end{array}$ & $40 \%$ & $77 \%$ \\
\hline 3 & $\begin{array}{c}\text { If Swasta (T2) } \\
\text { then Shabu (N1) }\end{array}$ & $24 \%$ & $77 \%$ \\
\hline 4 & $\begin{array}{c}\text { If Lubuk Alung } \\
\text { (K3), Shabu } \\
\text { (N1) then } \\
\text { Wiraswasta (T1) }\end{array}$ & $12 \%$ & $63 \%$ \\
\hline 5 & $\begin{array}{c}\text { If Lubuk Alung } \\
\text { (K3) then Shabu } \\
\text { (N1) }\end{array}$ & $19 \%$ & $67 \%$ \\
\hline
\end{tabular}

Adapun hasil dari rule yang paling memenuhi kebutuhan adalah Jika Tempat Kejadian Perkara di Lubuk Alung dan Jenis Narkoba Shabu maka Tersangka adalah Wiraswasta. Hasil dari rule tersebut yang akan dijadikan pertimbangan dalam kasus Penyalahgunaan Narkoba 


\section{KESIMPULAN}

Berdasarkan analisa dan hasil maka dapat disimpulkan hal-hal yang terkait dengan penelitian ini. Setelah dilakukan pengujian kemudian didapatkan beberapa hubungan antara Tersangka, Tempat Kejadian Perkara dan Jenis Narkoba yang menggunakan algoritma Association Rule dengan metode FP-Growth. Adapun kesimpulan yang didapatkan sebagai berikut: Penerapan algoritma FP-Growth dapat membantu dalam mengelompokkan variabel-variabel pada sebuah kasus dan menghasilkan pengetahuan baru tentang kasus Penyalahgunaan Narkoba dapat dijadikan kewaspadaan masyarakat agar terhindar dari tindakan penyalahgunaan narkoba. Metode Fp-Growth dapat menghasilkan frequent Itemset dari FP-Tree, sehingga dapat diketahui tingkat penyalahgunaan narkoba apa yang sering dilakukan. Menguji software tools (Weka) dan kasus penyalahgunaan narkoba bahwa yang sebagaian besar melakukan tindak penyalahgunaan narkoba adalah Tempat Kejadian Perkara di Lubuk Alung yang memakai Jenis Narkoba yaitu Shabu dan Tersangkanya adalah Wiraswasta, Pengujian dalam penelitian ini mempinyai kombinasi terbaik yaitu Jika Tempat Kejadian Perkara di Lubuk Alung dan Jenis Narkoba Shabu maka Tersangka adalah Wiraswasta.

\section{DAFTAR PUSTAKA}

Domma Lingga. 2016. Penerapan Algortima Apriori Dalam Memprediksi Persediaan Buku Pada Perpustakaan SMA Dwi Tunggal Tanjung Morawa. Program Studi Teknik Informatika STMIK Budidarma Medan

Subrata Datta, Kalyani Mali. 2016 Trust A New Objective Measure For Symmetric Association Rule Mining In Account Of Dissociation And Null Transaction. Department of Information Technology Neotia Institute of Technology, Management \& Science

Thanh Thi Bi Dan, Sari Widya Sihwi, Rini Anggrainingsih. 2015 Implementasi Iterative Dichotomiser 3 Pada Data Kelulusan Mahasiswa Di Universitas Sebelas Maret. Jurusan Informatika Universitas Sebelas Mare

Ali Ikhwan, Dicky Nofriansyah, Sriani. 2015. Penerapan Data Mining dengan Algoritma Fp-Growth untuk Mendukung Strategi Promosi Pendidikan ( Studi Kasus Kampus STMIK Triguna Dharma) Padang : Program Studi Sistem Komputer. 
Parasian Silitongga. 2016. Analisa Penyebaran Penyakit Pasien Pengguna Badan Penyelenggara Jaminan Sosial (BPJS) Kesehatan Dengan Menggunakan Metode DBSCAN Clustering (Studi Kasus Rumah Sakit Umum Pusat Haji Adam Malik Medan). Fakultas Ilmu Komputer Unika St. Thomas S.U.

K. Sumanthi, Phd, S. Kannan, Phd, K. Nagarajan. Data Mining Analysis of Student Database Using Classifation Tehniques. Departement of CS and IT, Kalasalingan University, Krishnan Kovil.

Mohamad Irfan. 2015. Analisa Pola Asosiasi Jalur Masuk Terhadap Kelulusan Mahasiswa Dengan Menggunakan Metode Fold - Growth (Studi Kasus Fakultas Sains Dan Teknologi). Jurusan Teknik Informatika, Fakultas Sains dan Teknologi Universitas Islam Negeri Sunan Gunung Djati Bandung.

Rizky Fitria, Warnia Nengsih, Dini Hidayatul Qudsi. 2017. Implementasi Algoritma FP-Growth Dalam Penentuan Pola Hubungan Kecelakaan Lalu Lintas. Program Studi Sistem Informasi, Politeknik Caltex Riau, Jl. Umban Sari (Patin) No.1 Rumbai Pekanbaru.

Elsa Widiati, S.Kom, Kania Evita Dewi, S.Pd, M.Si. 2014. Implementasi Association Rule Terhadapa Penyusunan Layout Makanan dan Penentuan Paket Makanan Hemat di RM Roso Echo Dengan Algoritma Apriori. Teknik Informatika UNIKOM Bandung.

Budanis Dwi Melaini, Muhammad Asadulloh. 2015. Data Mining Untuk Menggali Pola Mahasiswa Baru Menggunakan Metode Frequent Pattern Growth (Studi Kasus Institut Teknologi Adhi Tama Surabaya). Jurusan Teknik Informatika, Institut Teknologi Adhi Tama Surabaya.

Lismardiana, Herman Mawengkang, Erna Budhiarti Nababan. 2015 Pengembang Algortima Apriori Untuk Pengambilan Keputusa. Magister S2 Fasilkom TI Universitas Sumatera Utara Medan. 
Chenlu Li, Xiangjun Dong, Xue Dong, Xiaoqiang Ren. 2016. FP-Growth Based Method for Mining Infrequent and Frequent Itemset With 2 Level Minimun Support. School of Information Qilu University Of Technology Jinan, China.

Budanis Dwi Meilani, Azmuri Wahyu Azinar. 2015. Penentuan Pola yang sering muncul untuk penerima Kartu Jaminan Kesehatan Masyarakat (JAMKESMAS) Menggunakan Metode FP-Growth. Sistem Informasi Fakultas Teknologi Informasi Institut Teknologi Adhi Tama Surabaya.

Qomariyatus Sholihah. 2015. Efektivitas Program P4GN Terhadap Pencegahan Penyalahgunaan Napza. Program Studi Kesehatan Masyarakat Fakultas Kedokteran Universitas Lambung Mangkurat.

Arif Hidayat. 2015. Diseminasi Kesadaran Hukum Guna Penguatan Daya Tangkal Mandiri Terhadap Penyalahgunaan Narkoba dan Perilaku Seks Bebas di Kalangan Remaja Kecamatan Bandungan Kabupaten Semarang. Fakultas Hukum Universitas Negeri Semarang.

Khamimatuz Zulfa, Eny Purwandari. 2016. Pola Keluarga Remaja Berisiko Penyalahgunaan NAPZA. Fakultas Psikologi Universitas Muhammadiyah Surakata.

Elviza Ramhadona, Helfi Agustin. 2014. Faktor yang berhubungan dengan Penyalahgunaan Narkoba di RSJ Prof. HB. Sa'anin. Fakultas Kesehatan Masyarakat, Universitas Baiturrahmah, Padang, Sumatera Barat.

RN Ichsan, E Surianta, L Nasution, 2019. Pengaruh Disiplin Kerja Terhadap Kinerja Pegawai Negeri Sipil (PNS) Dilingkungan Ajudan Jenderal Daerah Militer (AJENDAM) -I Bukit Barisan Medan, Jurnal Darma Agung 28(2), 187-210.

Lukman Nasution, Reza Nurul Ichsan, Mega Arisia Dewi, Buyung Perdana Surya, Efriyani Sumastuti, 2020. Emerging Supply and Demand as a Mix of Social, Economic, and Psychological Factors, Journal of critical reviews JCR. 2020; 7 (17) : 421-424.

Jonner Lumban Gaol, Reza Nurul Ichsan, Lamminar Hutabart, 2020. The effect of working atmosphereand discipline towardemployee work productivity pt. Duta 
margalestarindomedan, Journal of Advanced Research in Dynamical and Control Systems (2020), Pages:554-564. 